\title{
Danish clinical quality databases - an important and untapped resource for clinical research
}

This article was published in the following Dove Press journal:

Clinical Epidemiology

25 October 2016

Number of times this article has been viewed

\author{
Henrik Toft Sørensen' \\ Lars Pedersen' \\ Jørgen Jørgensen ${ }^{2}$ \\ Vera Ehrenstein' \\ 'Department of Clinical Epidemiology, \\ Aarhus University Hospital, Aarhus, \\ ${ }^{2}$ Danish Regions, Copenhagen, \\ Denmark
}

Correspondence: Henrik Toft Sørensen Department of Clinical Epidemiology, Aarhus University Hospital, Olof Palmes Allé 43-45, 8200 Aarhus N, Denmark Tel +4587168215

Fax +458716 7215

Email hts@clin.au.dk
The health care systems in many countries are facing several challenges: the aging population, the need for personalized medicine, evolving treatment modalities, quality and safety imperatives, and unsustainable costs, to mention only a few. Population aging in the face of significant pressure to contain costs is perhaps the most immediate challenge. The proportion of people aged 65 years or older in Western Europe and North America is expected to increase to $26 \%$ in 2025 . Furthermore, clinical medicine in the Western world is confronting an evolving set of diseases, as smoking becomes less prevalent and obesity more common. Diagnostics and treatment of chronic disease have improved, while the threshold for initiating preventive treatment of asymptomatic conditions has been lowered. Consequently, the number of patients with multimorbidity, that is, the coexistence of several chronic diseases, will increase dramatically. ${ }^{1}$ To treat a disease or prevent its progression, patients with several chronic diseases often take multiple drugs, each with potentially severe side effects. In patients with multiple morbidities, "polypharmacy" is a challenging clinical issue, often associated with iatrogenic harm. ${ }^{2}$ A call for innovative approaches to polypharmacy has been the focus of recent editorials in high-impact medical journals..$^{3-5}$ Randomized trials rarely address multimorbidity, adherence to treatments, co-intervention (polypharmacy), or their long-term risks. ${ }^{6}$ These challenges underscore the need for population-based long-term longitudinal clinical data available for clinical care and research.

The Nordic countries have a long history of registration of health events using disease and administrative registries. The first disease registry in the world - the Leprosy Registry in Norway - was established as early as $1856 .{ }^{7}$ In the 20th century, registries on causes of death, tuberculosis, and cancer (in Denmark, in 1943) were added. The establishment of the National Population Registry with a personal registration number, in 1968 in Denmark (and similar registries in other Nordic countries), opened the possibility of lifelong collection of information on the same person in all independent registries in the given country throughout each person's entire lifetime. ${ }^{8}$ This is a rather unique situation for Denmark and the other Nordic countries compared with other countries. Thanks to recent technological developments, Denmark has established dozens of medical registries over the last decades as a part of the public administration of the health care system and related areas. It is a constellation of three conditions universal health care, individual linkage, and a long tradition of longitudinal routine 
data collection - that makes Denmark and other Nordic countries an ideal place of epidemiologic research.

Over the recent decades, the clinical quality databases, a new group of medical databases, have evolved in Denmark. Many of these databases had been founded and initially operated by enthusiastic clinicians. ${ }^{9}$ These databases typically cover all patients with a specific disease (eg, colorectal cancer) or those undergoing a specific surgical procedure (eg, hip replacement). In 2001, Danish Regions (formerly counties) established an administrative infrastructure for approval and support of the clinical quality databases with the aim of meeting the need for monitoring the clinical quality and patient safety. Since 2006, there has been a specific procedure in place to improve and operate the clinical quality databases, and since 2011 they have been organized in an administrative structure, the Danish Clinical Registers. ${ }^{10}$ To obtain approval and public funding, the program requires that a database cover at least $90 \%$ of the patients with a disease in the Danish hospital system. Similar programs exist in the other Nordic countries, whose combined population is $>25 \mathrm{~m}$ individuals. Obviously, these databases have a huge research potential because they represent complete cohorts of patients with verified diagnoses, detailed clinical data, and possibility for complete and longitudinal follow-up. The Novo Nordisk Foundation and the Lundbeck Foundation have recognized the potential and have provided a grant to the Danish Regions with the aim of improving the research potential of the clinical quality databases. This has resulted in a series of papers published in this Thematic Series of Clinical Epidemiology, in which most of these clinical quality databases are described in detail.

However, several challenges must be overcome before the research potential of the clinical quality databases is fulfilled. Given the wide spread of multimorbidity, it is a challenge that the patients' clinical history is recorded in 60 separate databases. To use the data for research, an approval is required from each database, which is associated with a substantial lag time. Moreover, we do not know in which individual clinical databases the patients are recorded. The large number of individuals living for years with chronic disorders such as osteoarthritis of the hip or knee, obesity, diabetes, cancer, and vascular diseases exemplifies the problems.

Personalized medicine is a rapidly advancing concept, entailing medical decision-making and treatment customized to individual patients using genetic or other clinical information. ${ }^{11}$ This approach was practiced by clinicians long before the term "personalized medicine" was introduced. For example, oncology has a long history of adjusting treatment according to tumor stage and anatomical and pathological findings. ${ }^{12}$ New technologies permit rapid, inexpensive, and comprehensive molecular profiling of a large number of individuals. ${ }^{13,14}$ As a result, many biobanks have been established in Denmark such as the Danish National Biobank and the Danish Cancer Biobank. ${ }^{15,16}$ A crucial element for personalized medicine in the future is comprehensive description of patients' phenotypes (observed physical/ biological characteristics), since changes in phenotype are one of the most valid manifestations of altered gene function. ${ }^{17}$ In combination with clinical databases and registries, the biobanks provide excellent opportunities for research on personalizing medicine. However, for these biobanks to reach their full potential, high-quality data are needed on disease severity, response to therapy, comorbidity, and adverse effects. Improved descriptions of patients' phenotypes are therefore extremely important to optimize utilization of Danish biobanks in clinical research. Information combining the best evidence on benefits and safety is needed for daily clinical practice. Whenever a patient and a physician decide on a particular course of treatment, they expect the benefits to exceed the harms. While medical advances offer accurate diagnostic and treatment information that might optimize patient outcomes, ${ }^{18}$ the exploding number of diagnostic and treatment combinations also poses significant risk of diagnostic and therapeutic error. ${ }^{3}$ Preventable iatrogenic infections and venous thromboembolism have been estimated to cause 200,000 deaths annually in the USA, ${ }^{19}$ and many thousands of deaths are associated with diagnostic errors. ${ }^{20,21}$ This further stresses the need for updated clinical data and easy access to the entire medical history for treating physicians. We call this approach electronic personalized medicine and it is prerequisite for high-quality clinical care.

Denmark has unrealized potential to meet the challenge of understanding the benefits, risks, and costs of clinical care. The Program for Clinical Research Infrastructure initiative is the first step in this process that brings together research and clinical practice. Development of the health care system and the technological development will lead to a substantial number of opportunities in the future. However, it requires comprehensive integration of clinical epidemiology, biostatistics, and clinical quality to translate these issues into clinical care. The data agencies in charge have a responsibility to make the data available for research and clinical care progress. The data are collected by the clinicians in the hospitals and form a substantial resource. We, researchers and clinicians, given the goldmine of data from everyday clinical practice, generously provided to us by patients for many decades, have 
the ethical obligation to give these data back to the future generations of patients in the form of research that serves improvement of health and well-being.

\section{Acknowledgment}

Henrik Toft Sørensen and Jørgen Jørgensen are funded by the Program for Clinical Research Infrastructure (PROCRIN) established by the Lundbeck Foundation and the Novo Nordisk Foundation.

\section{Disclosure}

The authors report no conflicts of interest in this work.

\section{References}

1. Tinetti ME, Fried TR, Boyd CM. Designing health care for the most common chronic condition - multimorbidity. JAMA. 2012;307: 2493-2494.

2. Lees J, Chan A. Polypharmacy in elderly patients with cancer: clinical implications and management. Lancet Oncol. 2011;12:1249-1257.

3. Pronovost PJ, Goeschel CA. Time to take health delivery research seriously. JAMA. 2011;306:310-311.

4. Salisbury C. Multimorbidity: redesigning health care for people who use it. Lancet. 2012;380:7-9.

5. The Lancet. How to cope with an ageing population. Lancet. 2013; 382:1225.

6. Sørensen HT, Lash TL, Rothman KJ. Beyond randomized controlled trials: a critical comparison of trials with nonrandomized studies. Hepatology. 2006;44:1075-1082.

7. Hansen AG, Looft C. Leprosy: In Its Clinical \& Pathological Aspects. Bristol: John Wright \& Co; 1973.
8. Schmidt M, Pedersen L, Sørensen HT. The Danish Civil Registration System as a tool in epidemiology. Eur J Epidemiol. 2014;29:541-549.

9. Green A. Danish clinical databases: an overview. Scand J Public Health. 2011;39(7 Suppl):68-71.

10. Nørgaard M, Johnsen SP. How can the research potential of the clinical quality databases be maximized? The Danish experience. J Intern Med. 2016;279:132-140.

11. Jameson JL, Longo DL. Precision medicine - personalized, problematic, and promising. N Engl J Med. 2015;372:2229-2234.

12. Baron JA. Screening for cancer with molecular markers: progress comes with potential problems. Nat Rev Cancer. 2012;12:368-371.

13. Chen R, Mias GI, Li-Pook-Than J, et al. Personal omics profiling reveals dynamic molecular and medical phenotypes. Cell. 2012;148:1293-1307.

14. Whirl-Carrillo M, McDonagh EM, Hebert JM, et al. Pharmacogenomics knowledge for personalized medicine. Clin Pharmacol Ther. 2012;92:414-417.

15. The Danish National Biobank [homepage on the Internet]. Copenhagen: Statens Serum Institut. Available from: http://www.biobankdenmark dk/. Accessed May 20, 2016.

16. The Danish Cancer Biobank [homepage on the Internet]. Herlev: Herlev Hospital. Available from: http://www.cancerbiobank.dk/. Accessed May 20, 2016.

17. Pathak J, Kho AN, Denny JC. Electronic health records-driven phenotyping: challenges, recent advances, and perspectives. $J$ Am Med Inform Assoc. 2013;20:e206-e211.

18. Roque FS, Jensen PB, Schmock H, et al. Using electronic patient records to discover disease correlations and stratify patient cohorts. PLoS Comput Biol. 2011;7:e1002141.

19. McGlynn EA, Asch SM, Adams J, et al. The quality of health care delivered to adults in the United States. N Engl J Med. 2003;348:2635-2645.

20. Newman-Toker DE, Pronovost PJ. Diagnostic errors - the next frontier for patient safety. JAMA. 2009;301:1060-1062.

21. Landrigan CP, Parry GJ, Bones CB, Hackbarth AD, Goldmann DA Sharek PJ. Temporal trends in rates of patient harm resulting from medical care. N Engl J Med. 2010;363:2124-2134.

Dove Medical Press encourages responsible, free and frank academic debate. The content of the Clinical Epidemiology 'Editorial' section does not necessarily represent the views of Dove Medical Press, its officers, agents, employees, related entities or the Clinical Epidemiology editors. While all reasonable steps have been taken to confirm the content of each Editorial, Dove Medical Press accepts no liability in respect of the content of any Editorial, nor is it responsible for the content and accuracy of any Editorial.

Clinical Epidemiology

\section{Publish your work in this journal}

Clinical Epidemiology is an international, peer-reviewed, open access, online journal focusing on disease and drug epidemiology, identification of risk factors and screening procedures to develop optimal preventative initiatives and programs. Specific topics include: diagnosis, prognosis, treatment, screening, prevention, risk factor modification,

Submit your manuscript here: https://www.dovepress.com/clinical-epidemiology-journal
Dovepress

systematic reviews, risk and safety of medical interventions, epidemiology and biostatistical methods, and evaluation of guidelines, translational medicine, health policies and economic evaluations. The manuscript management system is completely online and includes a very quick and fair peer-review system, which is all easy to use. 